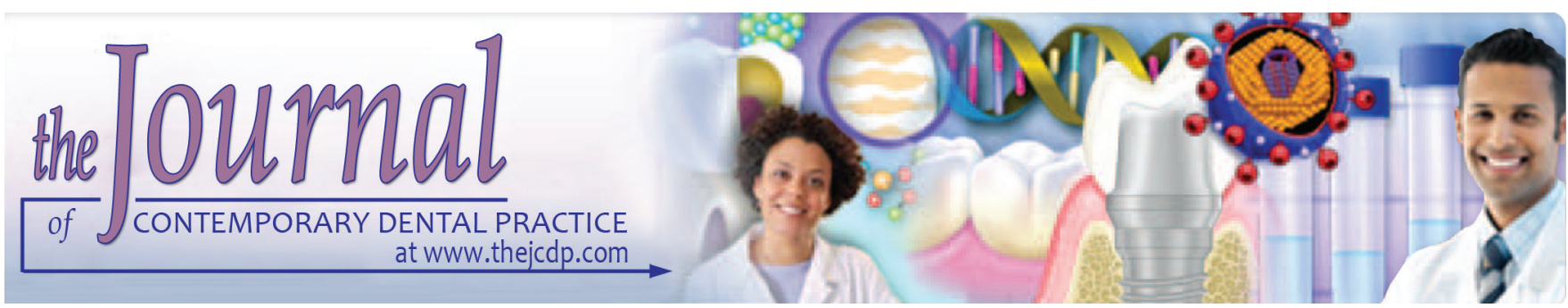

\title{
Influence of Age on Factors associated with Peri-implant Bone Loss after Prosthetic Rehabilitation over Osseointegrated Implants
}

\footnotetext{
${ }^{1}$ Rejane EL Pedro, ${ }^{2}$ João P De Carli, ${ }^{3}$ Maria SS Linden, ${ }^{4}$ Igor FP Lima, ${ }^{5}$ Luiz R Paranhos
}

${ }^{6}$ Max D Costa, ${ }^{7}$ Ângelo JG Bós

\begin{abstract}
Introduction: To verify the influence of age on factors associated with peri-implant bone loss after prosthetic rehabilitation over osseointegrated implants.
\end{abstract}

Materials and methods: This is an analytical, observational, and longitudinal study with initial 23 participants. Patients presenting with osseointegrated implants with their respective prostheses installed were included, and they could be carriers of chronic and degenerative diseases, such as diabetes, osteoporosis, hypothyroidism, cardiovascular disease (CVD), and systemic arterial hypertension. Thus, 18 participants with 57 implants were selected and followed up from 2009 to 2013. For statistical analysis, chi-square or Fisher's exact test was used for the association of systemic conditions and bone loss. Student's t-test was used for mean comparisons of age and number of total upper and lower implants.

Results: The average age of the sample studied was 71.05 years (65-80). The average implant per person was 3.2. Smoking had an influence on both mesial and distal bone loss, and the latter was significant $(p=0.0370)$. The association between bone loss and gender was also significant $(p<0.05)$. Moreover, male gender and upper implants were factors significantly associated with bone loss. The systemic conditions, when isolated, did not have significant influence on implant survival.

\footnotetext{
${ }^{1,7}$ Department of Gerodontology, Pontifical Catholic University of Rio Grande do Sul, Porto Alegre, Rio Grande dos Sul, Brazil

${ }^{2,3}$ Department of Dentistry, Passo Fundo University, Passo Fundo, Rio Grande do Sul, Brazil

${ }^{4,5}$ Department of Dentistry, Federal University of Sergipe Lagarto, Sergipe, Brazil

${ }^{6}$ Department of Dentistry, University Tiradentes, Aracaju Sergipe, Brazil

Corresponding Author: Luiz R Paranhos, Department of Dentistry, Federal University of Sergipe, Lagarto, Sergipe, Brazil Phone: +5579991161896, e-mail: paranhos@ortodontista. com.br
}

Conclusion: Age is not a factor that, alone, contraindicates implant-rehabilitating therapy. On the contrary, smoking has a significant influence on dental implant survival. Systemic diseases, such as osteoporosis, hypothyroidism, diabetes, hypertension, and heart diseases, when controlled, are not contraindication factors.

Clinical significance: This study is relevant for assessing peri-implant bone loss in elderly patients, right after implant installation and over time. Therefore, it was possible to verify that age is not a limiting factor for this procedure. Controlled systemic diseases do not contraindicate implant installation, but smoking is a factor that affects implant survival.

Keywords: Aging, Case-control study, Chronic disease, Dental implants, Implants, Prostheses, Risk factors.

How to cite this article: Pedro REL, De Carli JP, Linden MSS, Lima IFP, Paranhos LR, Costa MD, Bós ÂJG. Influence of Age on Factors associated with Peri-implant Bone Loss after Prosthetic Rehabilitation over Osseointegrated Implants. J Contemp Dent Pract 2017;18(1):3-10.

Source of support: Nil

Conflict of interest: None

\section{INTRODUCTION}

Aging is a global physiological phenomenon, and with the increase in life expectancy, the concern of geriatric patients with oral health has been enhanced. ${ }^{1}$ Caries and periodontal disease are the main causes of dental loss. ${ }^{2}$ Such loss occurs very often in the elderly, ${ }^{2}$ influencing mastication, speech, and esthetics, also aggravating chronic systemic and nontransmissible diseases, such as diabetes and hypertension, which commonly occur in aging individuals. ${ }^{3}$ Considering the need for dental care in the elderly, the World Health Organization (WHO) has set a goal for the year 2020 to minimize the impact of oral and craniofacial diseases on health and psychosocial 
development. ${ }^{3}$ Thus, oral rehabilitation through osseointegrated implants has become an important instrument for promoting quality of life in the elderly. ${ }^{4}$

Current endosseous implants present a feature of integration with the human bone, known as osseointegration. Hence, implant-supported prostheses are currently the main form of rehabilitation for completely or partially edentulous elderly patients, providing retention and stability of the prosthetic device and allowing increased masticatory efficiency and safety, improved psychological factor and self-esteem, ${ }^{5}$ and consequently quality of life.

After oral rehabilitation with osseointegrated implants and prostheses installation, it is common for patients to lose contact with the professional who performed the oral rehabilitation, not showing up to return dental visits for follow-up and assessment of results of these procedures, which in Dentistry and, specifically, in Implantology are essential for the longevity of peri-implant health, thus compromising therapeutic success. ${ }^{6}$

The data analyzed for therapeutic success are periimplant tissue health, the state of prostheses installed, and patient satisfaction. However, some factors, such as osteoporosis contribute to implant failure, because bone disease has the potential to change bone quality and formation, thus affecting osseointegration. ${ }^{7}$ Other factors, such as smoking and alcoholism may also lead to the compromise of implant success. ${ }^{8}$ It is important to know the parameters that are directly related to implant success in elderly patients. Thus, the present work sought to verify the influence of age on factors associated with peri-implant bone loss after prosthetic rehabilitation over osseointegrated implants.

\section{MATERIALS AND METHODS}

This study was approved by the Research Ethics Committee in Human Beings (protocol \#11/05465).

\section{Type of Study and Sample Description}

It is an analytical, observational, and longitudinal study developed in the city of Passo Fundo, RS, Brazil, at the School of Dentistry of the University of Passo Fundo (FOUPF-RS).

Included in the study were patients with osseointegrated implants of external hexagon, regular diameter, and length ranging from 8.5 to $11.5 \mathrm{~mm}$ (Conexão Sistemas de Prótese ${ }^{\mathrm{TM}}$, Arujá, Săo Paulo, Brazil), with their respective prostheses installed. The patients could have chronic and degenerative diseases, such as diabetes, osteoporosis, hypothyroidism, CVD, and systemic arterial hypertension. All prostheses analyzed in the study were installed fixed prostheses from one to three elements. The initial sample included 23 individuals.
The patients selected were followed up for 4 years with clinical and radiographic examinations in the period from 2009 to 2013, from the moment of installation of such prostheses. Five individuals quit the assessments, resulting in a final sample of 18 patients with 57 implants and respective prostheses, assisted at the institution.

\section{Methods}

Periapical radiographs of the implant region with positioning gauge were taken, automatically processed, scanned, and measured by a specific image processing software (ImageTool ${ }^{\mathrm{TM}}$ 2.0, San Antonio, Texas, USA) in order to perform measures calculated for both mesial and distal aspects. After determining a reference point common to all implants and defined as the implant platform, bone resorption was calculated by comparing the marginal bone with the level of implant platform. Such bone levels had their measurements expressed in pixels. The implants were classified into two groups: The first group included implants with and without mesial or distal bone loss, and the second group included implants according to the type of bone loss - without loss and with unilateral or bilateral loss. The participants were questioned regarding their systemic health, analyzing the presence of chronic and degenerative diseases, such as diabetes, osteoporosis, hypothyroidism, CVD, and systemic arterial hypertension. Questions related to life habits, such as smoking, alcoholism, and bruxism were also verified. The nutritional analysis of patients was performed by the Mini Nutritional Assessment ${ }^{\mathrm{TM}}$ (MNA). ${ }^{9}$

\section{Data Analysis}

For statistical analysis, chi-square or Fisher's exact test was used to study the association between bone loss and gender, presence of osteoporosis, hypothyroidism, diabetes, hypertension, heart disease, bruxism, smoking, and alcoholism, as well as the improvement of the MNA score. Moreover, Student's t-test was used for mean comparisons of age, and number of total upper and lower implants among the participants with and without MNA score improvements. Univariate linear regression was used to observe the relation among the degree of bone loss, age, gender, presence of osteoporosis, hypothyroidism, diabetes, hypertension, heart disease, bruxism, smoking, and alcoholism. Significance levels (p) lower than 0.05 were considered statistically significant and levels between 0.05 and 0.1 were considered significance indicators. A program for data management and epidemiological analysis (EpiInfo ${ }^{\mathrm{TM}}$ 3.5.1. Atlanta, Georgia, USA) was used for all analyses. 


\section{RESULTS}

Eighteen individuals with average age of 71.05 years minimum of 65 and maximum of 80 years - participated in the research. The mean implant per person was 3.2, and a total of 57 implants were assessed. Among them, 47 implants were followed up for 4 years, and 10 implants were followed up for 2 years.

The annual differences in bone heights between the initial assessment and at 2 or 4 years were calculated for both mesial and distal aspects. Negative values meant bone loss and positive values meant bone gain. Implant distribution according to mesial or distal loss frequency for clinical variables is presented in Table 1.

Table 2 presents implant distribution according to the type of bone loss and clinical variables. From the 57 implants analyzed, 17 showed no loss, 13 presented unilateral loss, and 27 showed mesial and distal losses. For implants in men, $70.8 \%$ presented bilateral bone loss, contrasting with implants in women, where the rate was $30.33 \%$. Implants without loss were more frequent in women, considering that $42.4 \%$ of implants in women presented no bone loss. The association between bone loss and gender was significant $(\mathrm{p}<0.05)$. The distribution of the type of loss and the presence or absence of heart disease was a significance level indicator $(p<0.1)$. The remaining variables were not significant.

Linear regression was used to observe the relation between the annual difference in peri-implant bone level and the variables of the study. Initially, univariate regressions were performed with each factor being analyzed individually. The results are presented in Table 3. Negative coefficients represent mean bone loss associated with the factor, while positive coefficients represent bone gain. Thus, the presence of alcoholism, bruxism, and diabetes was associated with bone loss, although it was not significant. Bone height gain was associated with the presence of heart disease (significant), hypertension, and hypothyroidism. The variable of age was used numerically in such a way that the interpretation of its coefficient represents the mean difference of bone height gain (0.033 pixels) associated with 1 year of age difference. Implants in individuals that were 1 year older had a mean gain of 0.033 pixels per year.

Table 4 presents the results of the univariate model including the factors that presented $\mathrm{p}<0.2$ in the analysis. We observed that osteoporosis, heart disease, and implant site lost their significance when they were adjusted to other factors, such as gender, age, and smoking.

Table 1: Implant distribution according to mesial or distal loss frequency for clinical variables

\begin{tabular}{|c|c|c|c|c|c|}
\hline Percentage & Mesial loss & & Distal loss & & \\
\hline Gender & Yes & No & Yes & No & Total \\
\hline Female & $14(42.4)$ & $19(57.6)^{\star *}$ & $15(45.5)$ & $18(54.5)^{\star \star}$ & $33(57.9)$ \\
\hline Male & $19(79.2)$ & $5(20.8)$ & $19(79.2)$ & $5(20.8)$ & $24(42.1)$ \\
\hline \multicolumn{6}{|l|}{ Alcoholism } \\
\hline No & $27(55.1)$ & $22(44.9)$ & $28(57.1)$ & $21(42.9)$ & $49(86.0)$ \\
\hline Socially & $6(75.0)$ & $2(25.0)$ & $6(75.0)$ & $2(25.0)$ & $8(14.0)$ \\
\hline \multicolumn{6}{|l|}{ Bruxism } \\
\hline No & $18(52.9)$ & $16(47.1)$ & $22(64.7)$ & $12(35.3)$ & $34(59.6)$ \\
\hline Yes & $15(65.2)$ & $8(34.8)$ & $12(52.2)$ & $11(47.8)$ & $23(40.4)$ \\
\hline \multicolumn{6}{|c|}{ Hypothyroidism } \\
\hline No & $25(59.5)$ & $17(40.5)$ & $25(59.5)$ & $17(40.5)$ & $42(73.7)$ \\
\hline Yes & $8(53.3)$ & $7(46.7)$ & $9(60.0)$ & $6(40.0)$ & $15(26.3)$ \\
\hline \multicolumn{6}{|c|}{ Osteoporosis } \\
\hline No & $30(62.5)$ & $18(37.5)$ & $30(62.5)$ & $18(37.5)$ & $48(84.2)$ \\
\hline Yes & $3(33.3)$ & $6(66.7)$ & $4(44.4)$ & $5(55.6)$ & $9(15.8)$ \\
\hline \multicolumn{6}{|l|}{ Smoking } \\
\hline No & 27 (52.9) & $24(47.1)^{\star \star}$ & $28(54.9)$ & $23(45.1)^{\star \star}$ & $51(89.5)$ \\
\hline Former & $6(100.0)$ & $0(0.0)$ & $6(100.0)$ & $0(0.0)$ & $6(10.5)$ \\
\hline \multicolumn{6}{|l|}{ Diabetes } \\
\hline No & $32(57.1)$ & $24(42.9)$ & $33(58.9)$ & $23(41.1)$ & $56(98.2)$ \\
\hline Yes & $1(100)$ & $0(0.0)$ & $1(100.0)$ & $0(0.0)$ & $1(1.8)$ \\
\hline \multicolumn{6}{|c|}{ Hypertension } \\
\hline No & $23(62.2)$ & $14(37.8)$ & $25(67.6)$ & $12(32.4)^{*}$ & 37 (64.9) \\
\hline Yes & $10(50.0)$ & $10(50.0)$ & $9(45.0)$ & $11(55.0)$ & $20(35.1)$ \\
\hline \multicolumn{6}{|c|}{ Heart disease } \\
\hline No & $28(65.1)$ & $15(34.9)^{*}$ & $29(67.4)$ & $14(32.6)^{\star \star}$ & $43(75.4)$ \\
\hline Yes & $5(35.7)$ & $9(64.3)$ & $5(35.7)$ & $9(64.3)$ & $14(24.6)$ \\
\hline Total & $33(57.9)$ & $24(42.1)$ & $34(59.6)$ & $23(40.4)$ & $57(100.0)$ \\
\hline
\end{tabular}


Table 2: Implant distribution according to the presence of loss for clinical variables

\begin{tabular}{|c|c|c|c|c|}
\hline Percentage & Bone loss & & & \\
\hline Gender & No loss & Unilateral & Bilateral & Total \\
\hline Female & $14(42.4)$ & $9(27.3)$ & $10(30.3)^{\star *}$ & 33 (57.9) \\
\hline Male & $3(12.5)$ & $4(16.7)$ & $17(70.8)$ & $24(42.1)$ \\
\hline \multicolumn{5}{|l|}{ Alcoholism } \\
\hline No & $15(30.6)$ & $13(26.5)$ & 21 (42.9) & 49 (86.0) \\
\hline Socially & $2(25.0)$ & $0(0.0)$ & $6(75.0)$ & 8 (14.0) \\
\hline \multicolumn{5}{|l|}{ Bruxism } \\
\hline No & $11(32.4)$ & $6(17.6)$ & $17(50.0)$ & 34 (59.6) \\
\hline Yes & $6(26.1)$ & $7(30.4)$ & $10(43.5)$ & $23(40.4)$ \\
\hline \multicolumn{5}{|c|}{ Hypothyroidism } \\
\hline No & $12(28.6)$ & $10(23.8)$ & $20(47.6)$ & 42 (73.7) \\
\hline Yes & 5 (33.3) & $3(20.0)$ & 7 (46.7) & 15 (26.3) \\
\hline \multicolumn{5}{|c|}{ Osteoporosis } \\
\hline No & $13(27.1)$ & $10(20.8)$ & $25(52.1)$ & 48 (84.2) \\
\hline Yes & $4(44.4)$ & $3(33.3)$ & $2(22.2)$ & $9(15.8)$ \\
\hline \multicolumn{5}{|l|}{ Smoking } \\
\hline No & $17(33.3)$ & $13(25.5)$ & $21(41.2)^{\star *}$ & $51(89.5)$ \\
\hline Former & $0(0.0)$ & $0(0.0)$ & $6(100)$ & $6(10.5)$ \\
\hline \multicolumn{5}{|l|}{ Diabetes } \\
\hline No & $17(30.4)$ & $13(23.2)$ & $26(46.4)$ & 56 (98.2) \\
\hline Yes & $0(0.0)$ & $0(0.0)$ & $1(100)$ & $1(1.8)$ \\
\hline \multicolumn{5}{|c|}{ Hypertension } \\
\hline No & $9(24.3)$ & $8(21.6)$ & $20(54.1)$ & 37 (64.9) \\
\hline Yes & $8(40.0)$ & $5(25.0)$ & $7(35.0)$ & $20(35.1)$ \\
\hline \multicolumn{5}{|c|}{ Heart disease } \\
\hline No & $10(23.3)$ & $9(20.9)$ & $24(55.8)^{*}$ & $43(75.4)$ \\
\hline Yes & $7(50.0)$ & $4(28.6)$ & $3(21.4)$ & $14(24.6)$ \\
\hline Total & $17(29.8)$ & $13(22.8)$ & $27(47.4)$ & $57(100.0)$ \\
\hline
\end{tabular}

Table 3: Univariate regression analysis with factors related to loss or gain of bone mass

\begin{tabular}{lrll}
\hline Variable & Coefficient & $p$-value & $r^{2}$ \\
\hline Alcoholism (socially/not) & -2.127 & 0.22411 & 0.03 \\
Bruxism (Yes compared with No) & -0.782 & 0.52989 & 0.01 \\
Diabetes (Yes/No) & -0.231 & 0.96050 & 0.00 \\
Hypertension (Yes/No) & 0.799 & 0.53257 & 0.01 \\
Heart disease (Yes/No) & 2.987 & 0.03194 & 0.08 \\
Hypothyroidism (Yes/No) & 0.561 & 0.68633 & 0.00 \\
Age (years) & 0.033 & 0.54985 & 0.01 \\
Implant site (upper/lower) & -1.812 & 0.17974 & 0.03 \\
Osteoporosis (Yes/No) & 3.253 & 0.04852 & 0.07 \\
Gender (M/F) & -4.057 & 0.00056 & 0.20 \\
Smoking (former/No) & -6.687 & 0.00039 & 0.21 \\
\hline
\end{tabular}

The nutritional assessment of the 18 participants was performed through a MNA 9 questionnaire for each of the following assessments: Initial, 2 and 4 years. The MNA calculates two scores: Screening and global. Table 5 shows the distribution of participants regarding the improvement in screening score, frequency of gender, and number and site of implant. The rate of men with improved screening score was higher, as well as the number of total and lower implants, although none of these tests was significant.
Table 4: Initial model of all significant variables in the univariate model (controlled by the effect of the other variables)

\begin{tabular}{lcl}
\hline Variable & Coefficient & $p$-value \\
\hline Age & 0.036 & 0.5603 \\
Implant site (upper/lower) & -1.187 & 0.3188 \\
Heart disease (Yes/No) & 2.027 & 0.3024 \\
Osteoporosis (Yes/No) & 0.073 & 0.9746 \\
Gender (M/F) & -3.204 & 0.0101 \\
Smoking (former/No) & -3.899 & 0.0479 \\
& $\mathrm{r}^{2}=$ & 0.36 \\
\hline
\end{tabular}

Table 6 shows the distribution of participants regarding the improvement in global assessment score, gender frequency, and number of implants. Women presented higher rate of improvement in the global score. Participants with improved global score had lower mean number of implants than participants with no improvement.

\section{DISCUSSION}

This longitudinal work sought to verify the relation of age and factors associated with peri-implant bone loss after prosthetic rehabilitation over osseointegrated implants. Moreover, there was evidence of the significant influence 
Influence of Age on Factors associated with Peri-implant Bone Loss after Prosthetic Rehabilitation

Table 5: Participant distribution according to the improvement in MNA screening score, frequency of gender, and number of implants

\begin{tabular}{|c|c|c|c|c|c|}
\hline Gender (\%) & Improvement & No improvement & $p$-value & & \\
\hline Female & $5(38.5)$ & $8(61.5)$ & & & \\
\hline Male & $3(60.0)$ & $2(40.0)$ & & & \\
\hline \multirow[t]{2}{*}{ Total } & $8(44.4)$ & $10(55.6)$ & 0.3823 & & \\
\hline & Mean & $S D$ & Mean & $S D$ & \\
\hline Number of implants & 3.88 & 2.2952 & 2.60 & 1.5055 & 0.1746 \\
\hline Upper implants & 0.88 & 1.8077 & 0.90 & 0.9944 & 0.9706 \\
\hline Lower implants & 3.00 & 1.9272 & 1.70 & 1.3375 & 0.1105 \\
\hline
\end{tabular}

SD: Standard deviation

Table 6: Participant distribution according to the improvement in MNA global assessment score, frequency of gender, and number of implants

\begin{tabular}{|c|c|c|c|c|c|}
\hline Gender (\%) & Improvement & No improvement & $p$-value & & \\
\hline Female & $9(69.2)$ & $4(30.8)$ & & & \\
\hline Male & $2(40.0)$ & $13(72.2)$ & & & \\
\hline \multirow[t]{2}{*}{ Total } & $11(61.1)$ & $7(38.9)$ & 0.3823 & & \\
\hline & Mean & $S D$ & Mean & $S D$ & \\
\hline Number of implants & 2.73 & 1.4206 & 3.86 & 2.5448 & 0.2414 \\
\hline Upper implants & 0.45 & 0.8202 & 1.57 & 1.8127 & 0.0912 \\
\hline Lower implants & 2.27 & 1.8488 & 2.29 & 1.6036 & 0.9880 \\
\hline
\end{tabular}

SD: Standard deviation

of smoking on bone loss. However, systemic diseases, such as osteoporosis, hypothyroidism, diabetes, hypertension, and heart diseases, when controlled, are not contraindication factors for implant-rehabilitating therapy.

Aging is a physiological process that interferes directly with local bone quality and quantity. ${ }^{10}$ Several studies ${ }^{11-13}$ suggest that old age is a risk factor for implant-rehabilitating therapy, considering the rate of bone formation around the implants decreases with age. ${ }^{11,14}$ The human skeleton starts to lose bone naturally after 30 years of age, when it reaches a peak of bone density. ${ }^{15,16}$ However, it is known that failure rates in dental implants are multifactorial, which indicates no sufficient data to affirm that aging alone is a contraindication factor for dental implants. ${ }^{10}$ Our study found no significant correlation that contraindicates the installation of dental implants in elderly patients, except when associated with smoking and upper implants, considering that such results were statistically significant for bone loss.

We also found a significant correlation between gender and bone loss. Although women suffer more frequently with metabolic processes that hinder osseointegration, men presented higher frequency of mesial and distal bone loss. Women tend to take more care of themselves than men and seek dental assistance more often, which results in a lower potential for bone loss by oral pathological processes. ${ }^{17}$ The low search for health care by men occurs, mostly, by the social feature of masculinity performed by men, such as superiority, self-sufficiency, and dominance, which is a barrier for seeking care. ${ }^{17,18}$ The literature on the relation of gender and peri-implant bone loss is scarce, and the profile of patients that suffer with dental implant failures is still deficient. Thus, such findings suggest that men are more susceptible to implant failures, perhaps because they present higher frequency of habits, such as smoking than women. ${ }^{13}$

Smoking is one of the oldest addictions acquired by the human being. ${ }^{19}$ However, this lifestyle negatively influences health, and smokers are more susceptible to develop diseases. ${ }^{19}$ Several studies show that this addiction harms wound healing and causes problems in skeletal tissues, ${ }^{19-22}$ which represents a high potential risk factor and reduces dramatically the rate of implant success. ${ }^{21}$ Twito et $\mathrm{al}^{22}$ found that the rate of implant failure was higher in the group of smokers than in the group of nonsmokers, when assessing 7,608 implants. Our study likewise verified mesial and distal bone loss, indicating the direct relation of smoking with bone loss. This habit compromises healing and tissue repair due to the vasoconstrictor effect of nicotine, leading to tissue hypoxia, which hinders osseointegration and consequently implant success. ${ }^{20}$ Hence, implant survival becomes difficult. ${ }^{22}$

Dental implants and implant-supported prostheses are options often used for the rehabilitation of elderly patients. ${ }^{23}$ However, a great portion of these patients presents systemic conditions that may compromise implant-rehabilitating therapy. ${ }^{23}$ Systemic diseases are increasingly more frequent in the modern world, representing an important risk factor. ${ }^{24}$ Several studies ${ }^{24-26}$ have reported the association of these pathologies with the potential complications in dental implants. Authors ${ }^{24}$ 
showed a statistically significant increase in the relative risk of implant failure with diabetes, especially at the initial phase. Implants performed in women with osteoporosis and smokers showed 2.6 times more chances of failure. ${ }^{27}$ On the contrary, in our study, hypothyroidism, osteoporosis, and diabetes did not present an association between bone loss and gain. Such divergence may have occurred because of the limited amount of additional original data published on diabetes, considering many of these publications are case reports, which show a potential weakness at the moment of interpreting results.

In a female population aged between 48 and 70 years, where 19 women had osteoporosis and 20 represented a control group, it was suggested that the loss of an implant might not be exclusively addressed to osteoporosis. ${ }^{28}$ Similarly, another study ${ }^{27}$ verified that the rate of implant survival was $92.5 \%$ in a sample of women diagnosed with osteoporosis. Thus, it is true that there is no scientific evidence that contraindicates dental implants in patients with osteoporosis, even when added by the smoking factor.

Cardiovascular diseases are one of the most prevalent conditions worldwide, affecting more than one billion people ${ }^{29}$ wherein arterial hypertension is most frequently found. Such a condition is commonly associated with a combination of genetic and environmental factors, such as smoking, age, sedentary lifestyle, family history, and others. ${ }^{30,31}$ The literature on implants and their success or failure rates in patients with heart diseases is scarce. ${ }^{24}$ However, heart problems, such as hypertension are not considered factors that contribute to implant failure. ${ }^{24,32,33}$ The present study found no significant association for implant failure in patients with cardiovascular problems, therefore indicating that such pathology, when controlled, does not contraindicate implant-rehabilitating therapy. Similarly, hypothyroidism, bruxism, and alcoholism showed no statistically significant results for dental implant failures. In a population of 29 patients of the female gender with previous history of hypothyroidism, it was suggested that such condition does not present higher risk of implant failures. ${ }^{6}$ Moreover, studies ${ }^{14,34}$ suggest that such conditions are not factors that, alone, promote dental implant failures.

Investigating the type of bone loss is an important piece of clinical data for implant assessment. ${ }^{35}$ Marginal bone loss should be assessed by tomography, in order to verify the degree of bone loss after implant-rehabilitating therapy. In a sample of 26 patients that received dental implants, it was suggested that bone loss after 12 months presents normal values, with no influence of age and gender on bone loss. ${ }^{35}$ In our study, we verified that mesial and distal bone loss occurred and was more frequent for males, while implants without loss were verified more often in women, which indicated a significant association $(p<0.05)$ between bone loss and gender. Such divergence may have occurred due to the low value of sample and the short time (12 months) of reassessment for peri-implant bone loss of the study in question, while the assessment of our work lasted 4 years.

Postimplant nutritional status and quality of life are essential parameters to assess the success of implantrehabilitating therapy, ${ }^{36}$ considering that masticatory deficiency negatively interfered with diet. ${ }^{37,38}$ In the present study, we used the MNA questionnaire ${ }^{9}$ in order to verify the improvement and worsening of the screening score. Our study observed no significant differences for the improvement or worsening of nutritional parameters assessed by the MNA (Table 5). Moreover, none of the analyses on the improvement of the global score was significant (Table 6). Similarly, several studies ${ }^{36,39,40}$ showed no significant changes that compromised the masticatory function. Conversely, there is a significant improvement in masticatory efficiency in patients rehabilitated with implants. ${ }^{10,36,41}$ Such improvement may be explained by the change in eating habits and improved masticatory quality, thus promoting aging with quality of life. Therefore, the importance of the interdisciplinary work in the patient to be rehabilitated is highlighted, including the interaction of dentists and nutritionists aiming to promote a positive response for implant-rehabilitating therapy.

Thus, this study emphasizes that age alone is not a risk factor that contraindicates implant installation, as well as controlled systemic conditions. We believe that the results hereby reported are vital for the increase in success rates of implant-rehabilitating therapy and for the continuous advances in peri-implant dentistry. Hence, further studies should be performed in order to confirm such findings, especially on the relation of gender and bone loss.

\section{CONCLUSION}

Age is not a factor that, alone, contraindicates implantrehabilitating therapy. Moreover, systemic diseases, such as osteoporosis, hypothyroidism, diabetes, hypertension, and heart diseases, when controlled, are also not contraindication factors. On the contrary, smoking has a significant influence on dental implant survival.

\section{CLINICAL SIGNIFICANCE}

This study is relevant for assessing peri-implant bone loss in elderly patients, right after implant installation and over time. Therefore, it was possible to verify that age is not a limiting factor for this procedure. Controlled systemic diseases do not contraindicate implant installation, but smoking is a factor that affects implant survival. 


\section{REFERENCES}

1. Unlüer S, Gökalp S, Doğan BG. Oral health status of the elderly in a residential home in Turkey. Gerodontology 2007 Mar;24(1):22-29.

2. Du M, Jiang H, Tai B, Zhou Y, Wu B, Bian Z. Root caries patterns and risk factors of middle-aged and elderly people in China. Community Dent Oral Epidemiol 2009 Jun;37(3):260-266.

3. Carvalho JA, Rodríguez-Wong LL. A transição da estrutura etária da população brasileira na primeira metade do século XXI. Cad Saude Publica 2008 Mar;24(3):597-605.

4. Bakke M, Holm B, Gotfredsen K. Masticatory function and patient satisfaction with implant-supported mandibular overdentures: a prospective 5-year study. Int J Prosthodont 2002 Nov-Dec;15(6):575-581.

5. Novaes LC, de Albuquerque Seixas Z. Prótese total sobre implante: técnicas contemporâneas e satisfação do paciente [Complete dentures prosthesis in implants: contemporary techniques and satisfaction]. Int J Dent 2008 Aug;7(1):50-62.

6. Papaspyridakos P, Chen CJ, Singh M, Weber HP, Gallucci GO. Success criteria in implant dentistry: a systematic review. J Dent Res 2012 Mar;91(3):242-248.

7. Gaetti-Jardim EC, Santiago-Junior JF, Goiato MC, Pellizer EP, Magro-Filho O, Jardim Junior EG. Dental implants in patients with osteoporosis: a clinical reality? J Craniofac Surg 2011 May;22(3):1111-1113.

8. Zavanelli RA, Guilherme AS, Castro AT, Fernandes JM, Pereira RE, Garcia RR. Fatores locais e sistêmicos relacionados aos pacientes que podem afetar a osseointegração. Rev Gaúcha Odontol 2011 Jun;59:133-146.

9. Nestlé Nutritional Institute. Mini nutritional assessment [Internet]; [cited 2016 Jun 25]. Available from: http:/ /www. mna-elderly.com/.

10. Allen F, McMillan A. Food selection and perceptions of chewing ability following provision of implant and conventional prostheses in complete denture wearers. Clin Oral Implants Res 2002 Jun;13(3):320-326.

11. Shirota T, Ohno K, Suzuki K, Michi K. The effect of aging on the healing of hydroxylapatite implants. J Oral Maxillofac Surg 1993 Jan;51(1):51-56.

12. Bryant SR, Zarb GA. Osseointegration of oral implants in older and younger adults. Int J Oral Maxillofac Implants 1998 Jul-Aug;13(4):492-499.

13. Son SR, Choe BM, Kim SH, Hong YS, Kim BG. A study on the relationship between job stress and nicotine dependence in Korean workers. Ann Occup Environ Med 2016 Jun;28:27.

14. Ikebe K, Wada M, Kagawa R, Maeda Y. Is old age a risk factor for dental implants? Jpn Dent Sci Rev 2009 May;45(1): 59-64.

15. Heersche JN, Bellows CG, Ishida Y. The decrease in bone mass associated with aging and menopause. J Prosthet Dent 1998 Jan;79(1):14-16.

16. Warming L, Hassager C, Christiansen C. Changes in bone mineral density with age in men and women: a longitudinal study. Osteoporos Int 2002;13(2):105-112.

17. Courtenay WH. Engendering health: a social constructionist examination of men's health beliefs and behaviours. Psychol Men Masc 2000 Jan;1(1):4-15.

18. Mahalik JR, Good GE, Englar-Carlson M. Masculinity scripts, presenting concerns, and help seeking: implications for practice and training. Prof Psychol Res Pr 2003 Apr;34(2): 123-131.
19. Yanbaeva DG, Dentener MA, Creutzberg EC, Wesseling G, Wouters EF. Systemic effects of smoking. Chest J 2007 May;131(5):1557-1566.

20. McDaniel JC, Browning KK. Smoking, chronic wound healing, and implications for evidence-based practice. J Wound Ostomy Continence Nurs 2014 Sep-Oct;41(5):415-423.

21. Sørensen LT. Wound healing and infection in surgery: the pathophysiological impact of smoking, smoking cessation, and nicotine replacement therapy: a systematic review. Ann Surg 2012; 255(6):1069-1079.

22. Twito D, Sade P. The effect of cigarette smoking habits on the outcome of dental implant treatment. PeerJ 2014 Sep; 2:e546.

23. Renouard, F, Rangert B. Risk factors in implant dentistry: simplified clinical analysis for predictable treatment. 2nd ed. Chicago: Quintessence Pub Co; 2008. p. 1-18.

24. Bornstein MM, Cionca N, Mombelli A. Systemic conditions and treatments as risks for implant therapy. Int J Oral Maxillofac Implants 2009;(Suppl 24):12-27.

25. Beikler T, Flemmig TF. Implants in the medically compromised patient. Crit Rev Oral Biol Med 2003 Jul;14(4):305-316.

26. Diz P, Scully C, Sanz M. Dental implants in the medically compromised patient. J Dent 2013 Mar;41(3):195-206.

27. Holahan CM, Koka S, Kennel KA, Weaver AL, Assad DA, Regennitter FJ, Kademani D. Effect of osteoporotic status on the survival of titanium dental implants. Int J Oral Maxillofac Implants 2008 Sep-Oct;23(5):905-910.

28. Amorim MA, Takayama L, Jorgetti V, Pereira RM. Comparative study of axial and femoral bone mineral density and parameters of mandibular bone quality in patients receiving dental implants. Osteoporos Int 2007 May;18(5):703-709.

29. Chobanian AV, Bakris GL, Black HR, Cushman WC, Green LA, Izzo JL Jr, Jones DW, Materson BJ, Oparil S, Wright JT Jr, et al. The seventh report of the joint national committee on prevention, detection, evaluation, and treatment of high blood pressure: the JNC 7 report. JAMA 2003 May;289(19):2560-2572.

30. Snieder H, Harshfield GA, Treiber FA. Heritability of blood pressure and hemodynamics in African- and EuropeanAmerican youth. Hypertension 2003 Jun;41(6):1196-1201.

31. Kaplan MS, Nunes A. The psychosocial determinants of hypertension. Nutr Metab Cardiovasc Dis 2003 Feb;13(1): 52-59.

32. Van Steenberghe D, Jacobs R, Desnyder M, Maffei G, Quirynen $\mathrm{M}$. The relative impact of local and endogenous patient-related factors on implant failure up to the abutment stage. Clin Oral Implants Res 2002 Dec;13(6):617-622.

33. Moy PK, Medina D, Shetty V, Aghaloo TL. Dental implant failure rates and associated risk factors. Int J Oral Maxillofac Implants 2005 Jul-Aug;20(4):569-577.

34. Elsubeihi ES, Zarb GA. Implant prosthodontics in medically challenged patients: the University of Toronto experience. J Can Dent Assoc 2002 Feb;68(2):103-108.

35. Fernández AF, Mahumud FJ, Carrió CP, Oltra DP, Conejero J, Diago MP. Radiological assessment of peri-implant bone loss: a 12-month retrospective study. J Clin Exp Dent 2011;3(5): 430-434.

36. Wöstmann B, Simon T, Neuhäuser-Berthold M, Rehmann P. Pilot study on the influence of nutritional counselling and implant therapy on the nutritional status in dentally compromised patients. PLoS One 2016 Jan;11(1):e0147193. 
37. Brennan DS, Spencer AJ, Roberts-Thomson KF. Tooth loss, chewing ability and quality of life. Qual Life Res 2008Mar;17(2): 227-235.

38. Millwood J, Heath MR. Food choice by older people: the use of semi-structured interviews with open and closed questions. Gerodontology 2000 Jul;17(1):25-32.

39. Inukai M, John MT, Igarashi Y, Baba K. Association between perceived chewing ability and oral health-related quality of life in partially dentate patients. Health Qual Life Outcomes 2010 Oct;8:118.
40. Morais JA, Heydecke G, Pawliuk J, Lund JP, Feine JS. The effects of mandibular two-implant overdentures on nutrition in elderly edentulous individuals. J Dent Res 2003 Jan;82(1):53-58.

41. Müller F, Hernandez M, Grütter L, Aracil-Kessler L, Weingart D, Schimmel M. Masseter muscle thickness, chewing efficiency and bite force in edentulous patients with fixed and removable implant-supported prostheses: a cross-sectional multicenter study. Clin Oral Implants Res 2012 Feb;23(2): 144-150. 